\title{
CHARACTERIZATION OF PHARMACOKINETICS OF 2-((3-(CHLOROMETHYL)BENZOYL)OXY) BENZOIC ACID IN RATS BY USING HPLC-DAD METHOD
}

\section{CAROLINE, NATHANIA, KUNCORO FOE, SENNY YESERY ESAR, MARIA ANABELLA JESSICA*}

Faculty of Pharmacy, Widya Mandala Catholic University Surabaya (WMCUS), Indonesia

Email: marbel26.maj@gmail.com

Received: 11 Jun 2019, Revised and Accepted: 06 Aug 2019

\section{ABSTRACT}

Objective: A new compound of salicylic acid derivative, namely 2-((3-(chloromethyl)benzoyl)oxy)benzoic acid (3CBB), was synthesized to find a compound exhibiting higher analgesic activity and smaller ulcer irritation than acetylsalicylic acid (ASA). Therefore, this study aimed to investigate the pharmacokinetics of this new compound in rats, following a single dose oral administration of 3CBB (45 mg/kg BW).

Methods: Plasma samples of 9 healthy rats were collected before and up to $3 \mathrm{~h}$ after its oral administration, following an $18 \mathrm{~h}$ fasting period. Plasma concentrations of 3 CBB were determined using a validated HPLC-DAD assay. Pharmacokinetic parameters were determined using the compartment model technique. All experiments were carried out in triplicate.

Results: The pharmacokinetic parameters of $3 \mathrm{CBB}$ obtained were as follows: $\mathrm{T}_{\max }=28.9 \pm 1.1 \mathrm{~min}, \mathrm{C}_{\max }=0.57 \pm 0.02 \mu \mathrm{g} / \mathrm{ml}, \mathrm{AUC}$ total $=66.3 \pm 1.0 \mu \mathrm{g}$ $\mathrm{min} / \mathrm{ml}, \mathrm{K}_{\mathrm{el}}=0.018 \pm 0.002 \mathrm{~min}^{-1}$, and $\mathrm{T}_{1 / 2 \mathrm{el}}=39.4 \pm 3.9 \mathrm{~min}$. The long elimination half-life and low $\mathrm{C}_{\text {max }}$ indicated that $3 \mathrm{CBB}$ was extensively distributed in the deep and very deep tissues. This confirmed the unique and special characteristics of a highly lipophilic compound like $3 \mathrm{CBB}$ (log $\mathrm{P}=3.73$ ).

Conclusion: 3 CBB demonstrated a slower onset of action and longer elimination time from the body compared to ASA. Thus this new compound is a potential candidate to be developed as a new drug.

Keywords: 2-((3-(Chloromethyl)benzoyl)oxy)benzoic acid, Pharmacokinetics, Rat, HPLC-DAD

(C) 2019 The Authors. Published by Innovare Academic Sciences Pvt Ltd. This is an open access article under the CC BY license (http://creativecommons.org/licenses/by/4.0/) DOI: http://dx.doi.org/10.22159/ijap.2019v11i5.34536

\section{INTRODUCTION}

Acetylsalicylic acid (ASA, aspirin) has been used as a non-steroidal anti-inflammatory drug and antiplatelet agent for decades. After oral administration, ASA will be absorbed rapidly, mostly in the upper small intestine at the low $\mathrm{pH}$. The absorption of ASA follows first-order kinetics with the absorption half-life lies within the range from 5 to 16 min [1]. ASA is highly bound by plasma protein (99\%). It is hydrolyzed primarily in the liver, yielding salicylic acid. This is subsequently conjugated with glycine or glucuronic acid, and the conjugate is excreted mostly in urine [2]. The pharmacokinetic profile of ASA in rats after oral administration ( $40 \mathrm{mg} / \mathrm{kg} \mathrm{BW}$ ) was reported, with the following parameters area under the plasma concentration versus time curve from zero to infinity $\left(\right.$ AUC $\left._{0-\infty}\right)=152.2 \mu \mathrm{g} \mathrm{min} / \mathrm{ml}$, elimination half-life $\left(\mathrm{T}_{1 / 2}\right)=5.66 \mathrm{~min}$, peak plasma concentration $\left(\mathrm{C}_{\max }\right)=9.74$ $\mu \mathrm{g} / \mathrm{ml}$, and time to reach maximum drug concentration in plasma $\left(\mathrm{T}_{\max }\right)=7 \mathrm{~min}$ [3]. Meanwhile, other study reported the pharmacokinetics of ASA in human plasma after oral administration (500 mg/70 kg BW), with the following parameters: AUC $0-\infty=5.12 \mathrm{mg}$ $\mathrm{h} / \mathrm{ml} \mathrm{T}_{1 / 2}=0.422 \mathrm{~h}, \mathrm{C}_{\max }=4.84 \mu \mathrm{g} / \mathrm{ml}, \mathrm{T}_{\max }=0.5 \mathrm{~h} \mathrm{[4]}$.

Despite its ability to inhibit inflammation and its cardioprotective effect, many studies reported the harmful effect of ASA such as gastric irritation $[5,6]$.

To maintain the benefit of ASA and minimize its harmful effect, we have modified the structure of salicylic acid, by replacing the acetyl group with the benzoyl group, yielding a compound known as 2-( (3(chloromethyl)benzoyl)oxy)benzoic acid (3CBB) (fig. 1).<smiles>C=C(C)c1ccccc1C(=C)c1cccc(CC)c1</smiles>

Fig. 1: Chemical structure of $3 \mathrm{CBB}$
The benzoyl group is more lipophilic than the acetyl group, and hence increasing the ability of the molecule to penetrate the membrane which in turn will increase its pharmacological activity. In our previous study, we investigated the analgesic, toxicity and antiplatelet effects of 3CBB. This study demonstrated that our new compound is more active and less toxic than ASA [7].

To our knowledge, until now there is no study has reported the pharmacokinetic parameters of 3CBB. The pharmacokinetic profile may give a description of the onset of action, duration of action, and any side effects related to the 3 CBB level in the systemic circulation.

In this paper, we investigated the blood levels of this new compound with validated High Performance Liquid Chromatography UV method-Diode Array Detector (HPLC-DAD) [8, 9]. This study aimed to describe the pharmacokinetic profile of 3CBB in rats following oral administration, as a part of its development as a new drug.

\section{MATERIALS AND METHODS}

\section{Chemicals and reagents}

The material used in this study was 3 CBB, which was synthesized in our laboratory. The purity and identification of this compound were determined by using TLC, IR spectroscopy, ${ }^{1} \mathrm{H}-\mathrm{NMR},[13] \mathrm{C}-\mathrm{NMR}$ and The Element Energy Dispersive Spectroscopy (EDS) [7].

Methanol of HPLC grade was obtained from Merck (Germany), whereas acetonitrile, phosphoric acid and potassium dihydrogen phosphate of pro analytical grade were purchased from E. Merck (Germany). Distilled and deionized water was obtained from Otsuka (Indonesia), and pulvis gummi arabicum was purchased from Brataco (Indonesia).

\section{Instrumentation}

The HPLC system employed in this study was Hitachi L-2130 (Japan), $100 \mu \mathrm{L}$ injector (Rheodyne 7725, USA), DAD (Hitachi L-2455, Japan), and LiChroCART 250-4, LiChrospher 100 RP-18 (5 $\mu \mathrm{m}, 4250 \mathrm{~mm}$, Germany) as a stationary phase. Sample analysis was conducted isocratically using a mixture of methanol: phosphate buffer $\mathrm{pH} 4$ (4:6, $\mathrm{v} / \mathrm{v}$ ) as a mobile phase at the flow rate of $1.0 \mathrm{ml} / \mathrm{min}$. 
The other instruments used were pH meter (Metrohm 620, Switzerland), centrifuge (Zentrifugen Hettich EBA 8S, Germany), vortex (Thermolyne, Iowa), sonicator and degassing apparatus (Branson 1210, USA), filter holder and Whatman filter paper with $0.45 \mu \mathrm{m}$ pore size (Millipore), analytical balance (Denver, India), and micropipette (Socorex, Swiss).

\section{Animals}

Nine healthy Wistar rats (Rattus norvegicus), weighing 200 g, aged 2-3 mo were obtained from Pusvetma (Indonesia). Experimental animals were housed in a temperature-controlled room $\left(20-24^{\circ} \mathrm{C}\right)$ with a $12 \mathrm{~h}$ light/dark cycle. They were allowed to consume food and water ad libitum. All experiments performed in this study obtained the ethical clearance, as approved by The University of Gadjah Mada Committee on the Use and Care of Animals (No. 00090/04/IPPT/VII/2017), acting on behalf of the Indonesian Government.

\section{Preparation of stock and working standard solutions}

A stock standard solution of 3 CBB at a concentration of $4 \mathrm{mg} / \mathrm{l}$ was prepared by weighing and dissolving it in methanol. A solution of salicylic acid at a concentration of $0.24 \mathrm{mg} / \mathrm{l}$ in methanol was used as an internal standard. Working standard solutions were prepared by diluting an appropriate volume of the stock standard solution, yielding $0.15-4 \mathrm{mg} / \mathrm{l}$.

For the accuracy and precision study, an aliquot of the stock standard solution was diluted with $100 \mu \mathrm{l}$ of blank plasma to yield a series of concentrations of 3CBB in the range of $0.24-3.0 \mathrm{mg} / \mathrm{l}$. Fifty microliters of the internal standard solution were added into the aliquots and the resulting working standard solutions were transferred into $1.5 \mathrm{ml}$ tubes. Afterward, $300 \mu \mathrm{l}$ of acetonitrile was added into each tube, and then they were vortexed for $10 \mathrm{~min}$ and centrifuged at $3500 \mathrm{rpm}$ for $2 \mathrm{~min}$. The filtrate was collected and evaporated to dryness under nitrogen gas. The residue was dissolved in $50 \mu \mathrm{l}$ of mobile phase and was used as a sample.

\section{Validation study}

HPLC assay condition for bioanalytical method validation according to US FDA guidelines have been established [10]. The selectivity of this HPLC assay was tested by injecting samples, consisting of six blank plasma obtained from six rats. The presence of the 3CBB at a particular retention time was evaluated $[11,12]$.

A calibration curve was determined on each day of the $6 \mathrm{~d}$ validation period. Each HPLC run consisted of blank plasma, a zero calibrator (blank plasma with internal standard), and non-zero calibrators, comprising six working standard solutions at various concentrations ranging from $0.15-4 \mathrm{mg} / \mathrm{l}$.

The accuracy and precision (intra-day and inter-day variability) study were performed in triplicate during the $6 \mathrm{~d}$ validation period, employing five concentrations as quality control (QC) standard levels, ranging from $0.24-2.64 \mathrm{mg} / \mathrm{l}$. The accuracy and precision of this HPLC assay were expressed as Relative Error (\%) and Relative Standard Deviation (\%), respectively.

The stability of analyte in plasma during storage was performed, by analyzing the concentrations of this compound at three conditions, namely fresh-thaw after $0 \mathrm{~h}, 4 \mathrm{~h}$, and freeze-thaw $\left(24 \mathrm{~h}\right.$ at- $\left.20{ }^{\circ} \mathrm{C}\right)$. This study was performed in triplicate employing four QC concentrations $(0.25,0.5,3,4 \mathrm{mg} / \mathrm{l})$ that were freshly prepared.

\section{Pharmacokinetic study}

Prior to treatment, rats have fasted for $18 \mathrm{~h}$. The rats were anesthetized with ketamine intraperitoneal $(100 \mathrm{mg} / \mathrm{kg} \mathrm{BW})$ [13]. After $10 \mathrm{~min}$, animals were treated orally with $3 \mathrm{CBB}$ suspended in 1 $\mathrm{ml} 3 \%$ pulvis gummi arabicum, with a dose of $45 \mathrm{mg} / \mathrm{kg} \mathrm{BW}$. Blood samples were withdrawn from vena caudalis and collected into heparinized tubes, prior to dosing (time 0 ) and at pre-determined time intervals as follows $5,15,20,25,30,35,40,45,50,60,75,90$, 120 , and $180 \mathrm{~min}$. The collected blood sample was immediately centrifuged at $10,000 \mathrm{rpm}$ for $10 \mathrm{~min}$ to obtain plasma and then was stored at-20 ${ }^{\circ} \mathrm{C}$ prior to analysis. Plasma concentrations were determined using a validated HPLC assay. Pharmacokinetic parameters were determined using a compartment model technique. All experiments were carried out in triplicate.

\section{RESULTS AND DISCUSSION}

\section{Optimization of HPLC condition}

HPLC analytical method was performed isocratically using a mixture of methanol: phosphate buffer $\mathrm{pH} 4(4: 6, \mathrm{v} / \mathrm{v})$ as a mobile phase at the flow rate of $1.0 \mathrm{ml} / \mathrm{min}$. This was selected as the best HPLC assay condition, as it gave the best peak shape and resolution of peaks associated with salicylic acid and 3 CBB in plasma. A typical HPLC chromatogram demonstrating the peaks associated with blank plasma, $3 \mathrm{CBB}$, and internal standard is shown in fig. 2. No interference among peaks was observed, indicating the selectivity of this HPLC assay.

A calibration curve was obtained using six concentrations covering the linear range, in which each concentration was analyzed in six replicates. It was found that peaks associated with zero calibrators (blank plasma with endogenous substance) and internal standard did not interfere with the peak associated with 3CBB. The selected linear regression equation for $3 \mathrm{BB}$ used in this study was $\mathrm{y}=$ $251376 \mathrm{x}-22538$, demonstrating a good correlation between concentration $(\mathrm{x})$ and peak area $(\mathrm{y}) \mathrm{r}_{\text {calculated }}=0.99638>\mathrm{r}_{\text {table }}=$ 0.8114 ). In addition, $\mathrm{F}_{\text {calculated }}=0.145<\mathrm{F}_{\text {table }}=4.14$, indicating an insignificant difference between the calibration curves generated on each day of the $6 \mathrm{~d}$ validation period.

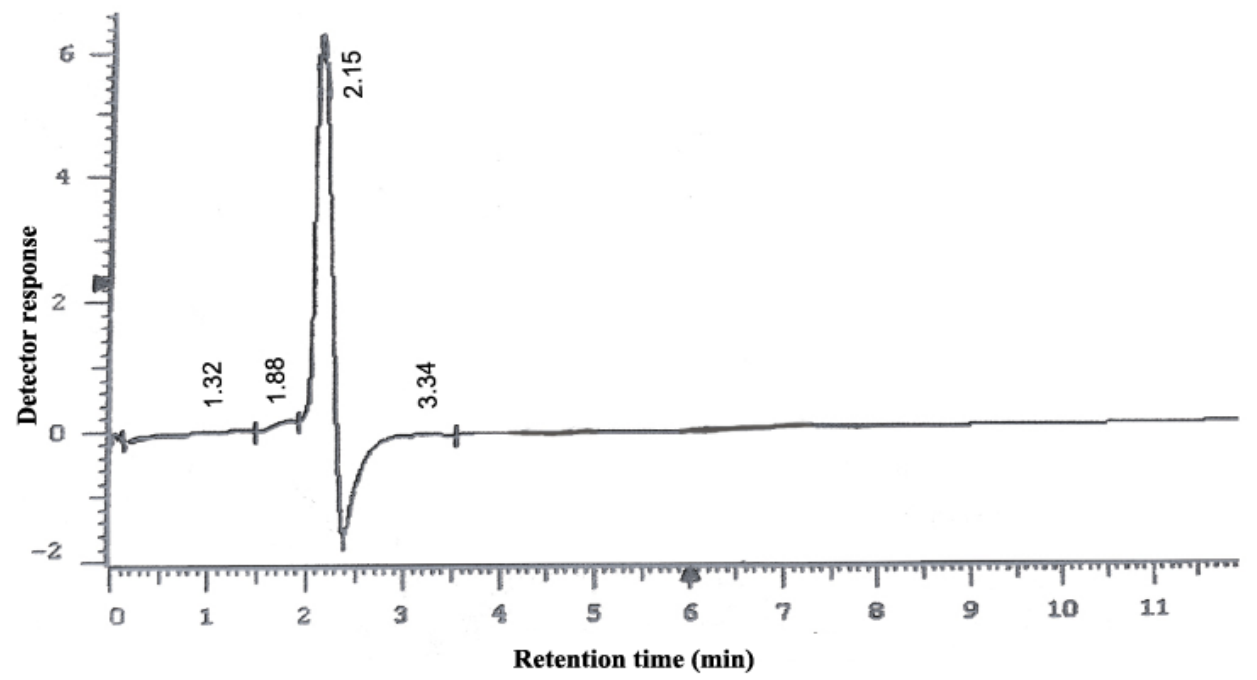

(a) 


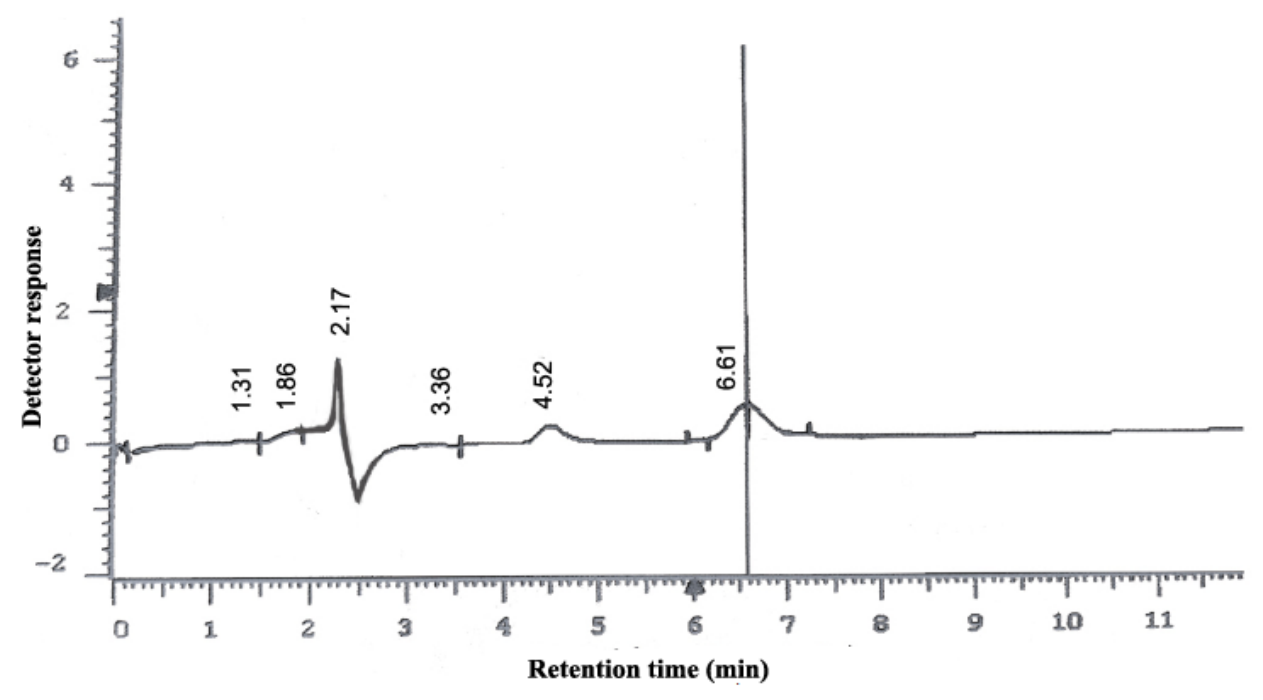

(b)

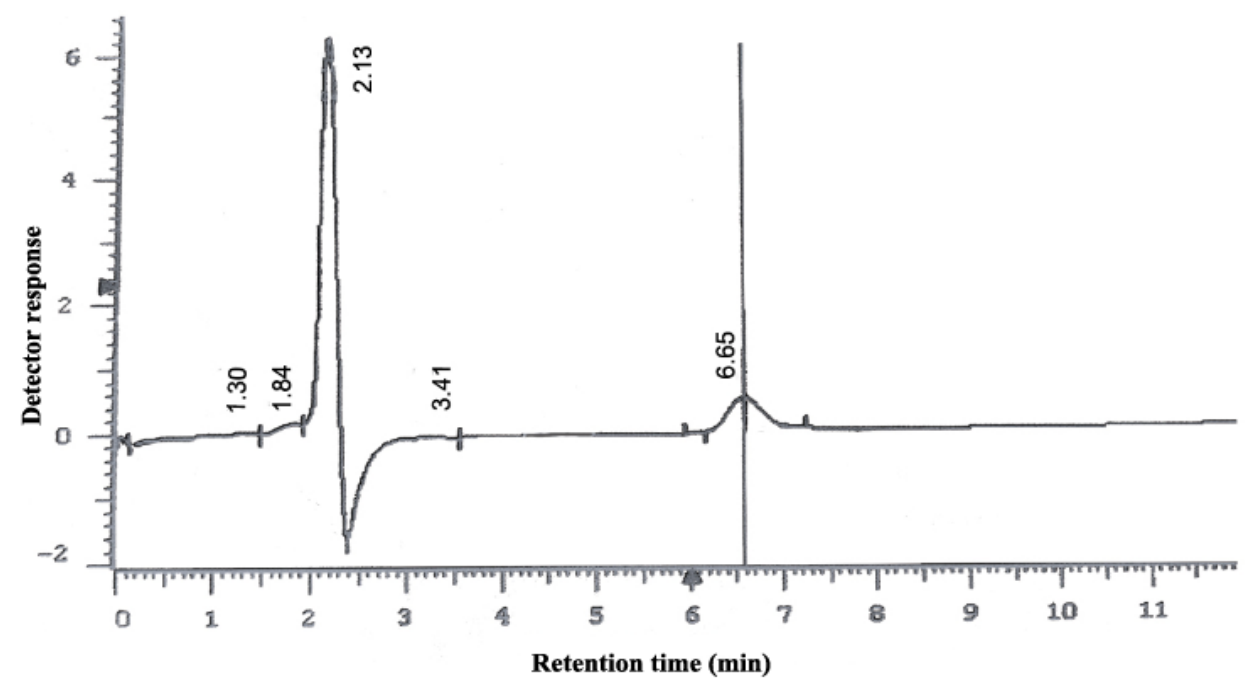

(c)

Fig. 2: Typical chromatogram profiles of: (a) Blank plasma, (b) Internal standard and 3CBB in plasma, (c) 3CBB in plasma. Notes: mobile phase was methanol: phosphate buffer $\mathrm{pH} 4(4: 6, \mathrm{v} / \mathrm{v})$ with the flow rate of $1 \mathrm{ml} / \mathrm{min}$; stationary phase/column was LiChrospher $100 \mathrm{RP}$ $18(5 \mu \mathrm{m}, 4 \times 250 \mathrm{~mm}$, Germany); detector was Diode Array Detector (DAD, Hitachi L-2455, Japan) at a wavelength of $231 \mathrm{~nm}$; retention times were $4.52 \mathrm{~min}$ for internal standard and $6.6 \mathrm{~min}$ for 3CBB

The LOQ (Limit of Quantitation) and LOD (Limit of Detection) values were found to be $0.1410 \mathrm{mg} / \mathrm{l}$ and $0.0423 \mathrm{mg} / \mathrm{l}$, respectively. Therefore this method was relatively sensitive to determine 3CBB.

The intra-day and inter-day variability of accuracy and precision studies of 3CBB are shown in table 1 . The relative error of intra-day and inter-day variability were found to be $0.32-1.33 \%$ and $0.46-$ $1.71 \%$, respectively. Meanwhile, the respective relative standard deviation of intra-day and inter-day variability were $0.05-0.62 \%$ and $0.12-0.80 \%$. Thus this HPLC assay was relatively accurate and precise to be employed in this study. The mean recovery of 3CBB in rat plasma was found to be $100.94 \% \pm 0.35 \%$.

Table 1: The intra-day and inter-day variability of accuracy and precision studies of 3 CBB

\begin{tabular}{|c|c|c|c|c|c|}
\hline \multirow{2}{*}{$\begin{array}{l}\text { Nominal concentration } \\
(\mu \mathrm{g} / \mathrm{ml})\end{array}$} & \multicolumn{2}{|c|}{ Intra-day variabilityc $^{c}$} & \multicolumn{2}{|c|}{ Inter-day variability $^{d}$} & \multirow{2}{*}{$\begin{array}{l}\text { Recovery }^{\mathrm{e}}(\%) \text { (Mean } \pm \\
\left.\text { RSD }^{\mathrm{b}}\right)\end{array}$} \\
\hline & $\begin{array}{l}\text { Accuracy (REa, } \\
\%)\end{array}$ & $\begin{array}{l}\text { Precision }\left(\mathrm{RSD}^{\mathrm{b}},\right. \\
\text { \%) }\end{array}$ & $\begin{array}{l}\text { Accuracy (REa, } \\
\%)\end{array}$ & $\begin{array}{l}\text { Precision }\left(\mathrm{RSD}^{\mathrm{b}},\right. \\
\text { \%) }\end{array}$ & \\
\hline 0.24 & 1.18 & 0.62 & 1.71 & 0.80 & $101.53 \pm 0.75$ \\
\hline 0.72 & 0.86 & 0.27 & 1.27 & 0.26 & $101.14 \pm 0.32$ \\
\hline 1.20 & 1.33 & 0.30 & 1.53 & 0.68 & $101.46 \pm 0.57$ \\
\hline 1.68 & 0.44 & 0.17 & 0.58 & 0.14 & $100.53 \pm 0.16$ \\
\hline 2.16 & 0.38 & 0.08 & 0.65 & 0.15 & $100.56 \pm 0.18$ \\
\hline 2.64 & 0.32 & 0.05 & 0.46 & 0.12 & $100.41 \pm 0.12$ \\
\hline
\end{tabular}

aRE: Relative Error $(\%)=($ actual concentration-nominal concentration $) /$ nominal concentration $\times 100 \%$, bRSD: Relative Standard Deviation $(\%)=$ Standard Deviation/mean of actual concentration $\times 100 \%,{ }^{c} n=3,{ }^{d} n=18,{ }^{e} n=21$ 
Table 2: Stability study of 3CBB in rat plasma

\begin{tabular}{|c|c|c|c|}
\hline \multirow{2}{*}{$\begin{array}{l}\text { Nominal } \\
\text { concentration }(\mu \mathrm{g} / \mathrm{ml})\end{array}$} & \multicolumn{2}{|c|}{ Fresh-thaw stability ${ }^{a}$} & \multirow{2}{*}{$\begin{array}{l}\text { Freeze-thaw Stability } \\
\left(-20^{\circ} \mathrm{C}, 24 \mathrm{~h}\right)\left(\text { mean } \pm \mathrm{RSD}^{\mathrm{b}}\right)\end{array}$} \\
\hline & $0 \mathrm{~h}\left(\right.$ mean $\left.\pm \mathrm{RSD}^{\mathrm{b}}\right)$ & $4 \mathrm{~h}\left(\right.$ mean $\left.\pm \mathrm{RSD}^{\mathrm{b}}\right)$ & \\
\hline 0.25 & $101.97 \pm 1.56$ & $101.08 \pm 0.68$ & $100.25 \pm 0.22$ \\
\hline 0.5 & $103.01 \pm 1.25$ & $102.04 \pm 1.62$ & $100.82 \pm 0.88$ \\
\hline 3 & $106.42 \pm 1.17$ & $104.11 \pm 1.28$ & $102.10 \pm 1.20$ \\
\hline 4 & $106.90 \pm 1.19$ & $105.81 \pm 1.20$ & $103.41 \pm 1.15$ \\
\hline
\end{tabular}

${ }^{a}$ n $=3$, bRSD: Relative Standard Deviation (\%)

The stability study of 3CBB in rat plasma is shown in table 2 . The sample was found to be stable during storage at- $20^{\circ} \mathrm{C}$ for $24 \mathrm{~h}$ and thus it could be used for pharmacokinetic study.

\section{Pharmacokinetic study}

The pharmacokinetic profile of 3 CBB in rat plasma is shown in fig. 3 . It exhibited a non-linear elimination phase, the plasma concentration of 3CBB increased slowly in the first 40 min and then rose and declined sharply within 40-60 min after oral administration. A tail-off profile was observed afterward. Previous studies $[3,14]$ reported that the pharmacokinetic profile of ASA increased dramatically in the first $5 \mathrm{~min}$ and then declined rapidly, whereas the concentration of its degradation product, salicylic acid constantly increased.

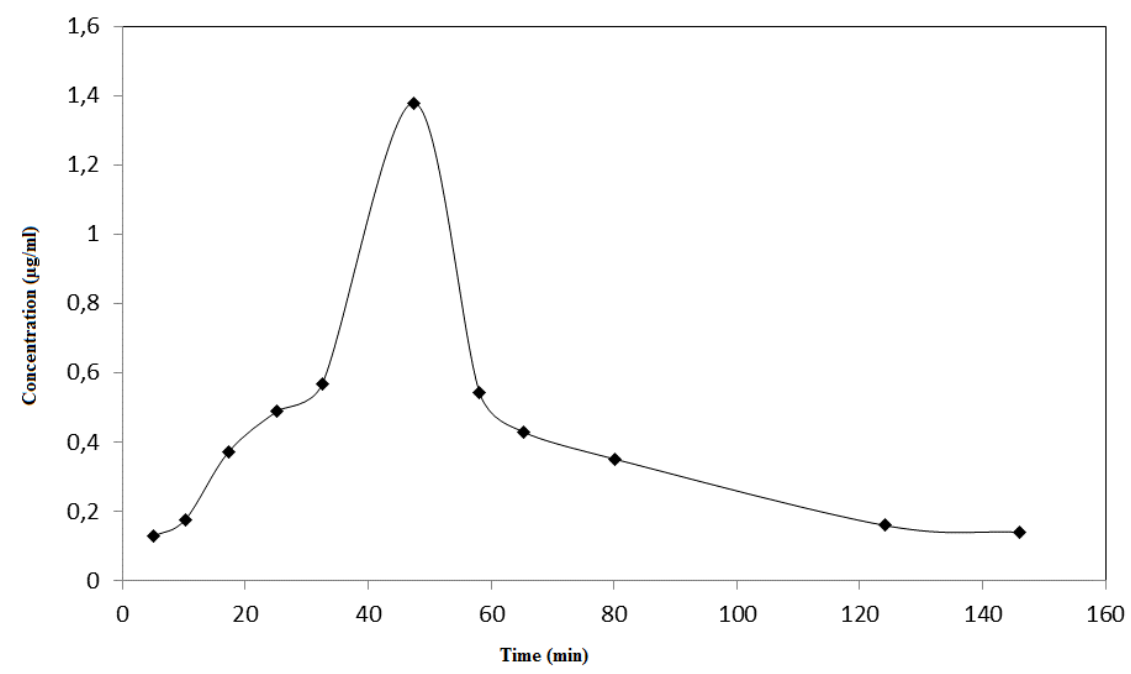

Fig. 3: A typical pharmacokinetic profile of 3 CBB in rat plasma following oral administration $(45 \mathrm{mg} / \mathrm{kg} \mathrm{BW}$ )

The value of $\mathrm{T}_{\max }$ is inversely proportional to the value of the absorption rate constant $\left(\mathrm{k}_{\mathrm{a}}\right)$. If there is an increase in $\mathrm{k}_{\mathrm{a}}$, it would cause a decrease in the value of $\mathrm{T}_{\max }$ and vice versa. The obtained $\mathrm{T}_{\max }$ value of $3 \mathrm{CBB}$ was $28.9 \pm 1.1 \mathrm{~min}$ (table 3), which is much longer than ASA (7 $\mathrm{min}$ ) as reported previously [3]. This study revealed that our new product exhibited a slower onset of action than ASA. This might be associated with its higher lipophilic properties and the stability of this product which was not easily hydrolyzed to yield salicylic acid.

Table 3: Calculated pharmacokinetic parameters of 3CBB in rat plasma after oral administration ( $45 \mathrm{mg} / \mathrm{kg} \mathrm{BW}$ )

\begin{tabular}{llll}
\hline Parameter & 3CBB $^{\mathbf{a}, \mathbf{d}}\left(\mathbf{m e a n} \pm \mathbf{R S D}^{\mathbf{e}}\right)$ & \multicolumn{1}{l}{ Acetylsalicylic acid } & [3] $^{\mathbf{c}}$ \\
\cline { 3 - 4 } & & [4] $^{\mathbf{b}}$ & - \\
$\mathrm{K}_{\mathrm{el}}\left(\mathrm{min}^{-1}\right)$ & $0.018 \pm 0.002$ & - & $5.66 \pm 1.27$ \\
$\mathrm{~T}_{1 / 2 \mathrm{el}}(\mathrm{min})$ & $39.4 \pm 3.9$ & $25.32 \pm 7.93$ & $7.0 \pm 1.6$ \\
$\mathrm{~T}_{\max }(\mathrm{min})$ & $28.9 \pm 1.1$ & 30 & $9.74 \pm 1.09$ \\
$\mathrm{C}_{\max }(\mu \mathrm{g} / \mathrm{ml})$ & $0.57 \pm 0.02$ & $4.84 \pm 1.73$ & $152.2 \pm 23.3$ \\
$\mathrm{AUC}_{0-\infty}(\mu \mathrm{g} \min / \mathrm{ml})$ & $66.3 \pm 1.0$ & $307.2 \pm 110.90$ & \\
\hline
\end{tabular}

a2-((3-(chloromethyl)benzoyl)oxy)benzoic acid, bPharmacokinetic study was performed in humans at a dose of 500 mg [4], cPharmacokinetic study was performed in Sprague Dawley rat at the dose of $40 \mathrm{mg} / \mathrm{kg}$ BW [3], ${ }^{\mathrm{d}} \mathrm{n}=9$, eRSD: Relative Standard Deviation (\%)

The following pharmacokinetic parameters were determined, including the time to reach the maximum concentration $\left(\mathrm{T}_{\max }\right)$, maximum concentration $\left(\mathrm{C}_{\max }\right)$, and the area under the curve of a plasma concentration versus time from 0 to infinity $\left(\mathrm{AUC}_{0-\infty}\right)$.

The maximum concentration of one particular drug in the systemic circulation highlights the intensity of the drug. $\mathrm{C}_{\max }$ is correlated with the volume of distribution (Vd). If there is an increase in Vd value, the value of $\mathrm{C}_{\max }$ will decrease and vice versa. Vd is very useful for estimating the relative amount of drug within the central or peripheral compartment. A large value of $\mathrm{Vd}$ indicates the higher amount of drug accumulating in the peripheral tissue compared to that in the central compartment. The $\mathrm{C}_{\max }$ value of this new compound was found to be $0.57 \pm 0.02 \mu \mathrm{g} / \mathrm{ml}$ (table 3 ). The low $\mathrm{C}_{\max }$ is associated with a large volume of distribution. Thus it could be hypothesized that this new compound was extensively distributed in the deep and very deep tissues. This phenomenon is commonly expressed by a highly lipophilic compound. This new compound, 3CBB, was reported to be more lipophilic $(\log P=3.73)$ than ASA $(\log \mathrm{P}=1.21)$ as reported in our previous study [7]. 
The $\mathrm{AUC}_{\text {total }}$ of $3 \mathrm{CBB}$ was found to be $66.3 \pm 1.0 \mu \mathrm{g} \mathrm{min} / \mathrm{ml}$ (table 3).

Elimination kinetics of one particular drug can be described by the parameter of elimination half-life $\left(\mathrm{T}_{1 / 2 \mathrm{el}}\right)$, the time required to reduce the blood drug level to half. Drugs can be cleared from the body through two main pathways namely kidneys and liver. Metabolism is a conversion process of the chemical structure of a drug in the body. In general, metabolism will convert the drug molecules to a more polar compound, that is more soluble in aqueous than fatty tissues, and hence it is more easily excreted through the kidneys. Metabolism reaction of the drug is facilitated by the presence of an enzyme, to yield an inactive compound. However, there are some metabolites that are more active and more toxic than their parent drugs. In this study the $\mathrm{T}_{1 / 2 \mathrm{el}}$ value obtained was $39.4 \pm 3.9 \mathrm{~min}$, which is much longer than the respective values of ASA 5,66 min in rats [3] and $25.32 \mathrm{~min}$ in humans [4]. Therefore $3 \mathrm{CBB}$ may require a much longer time for its elimination, compared to ASA.

\section{CONCLUSION}

This new compound, 3CBB, exhibited the slower onset of action and longer elimination time from the body, compared to ASA. This is in agreement with the lipophilic properties of 3 CBB compared to ASA. Thus this new compound, considering its pharmacological and toxicological properties, is a potential candidate to be developed as an alternative drug to substitute ASA.

\section{ACKNOWLEDGMENT}

This work was supported by the following grants: Ministry of Research, Technology and Higher Education of the Republic of Indonesia (115 W/WM01.5/N/2018 to K. F.). We also would like to thank Alexandra Christiyanti (Faculty of Pharmacy, Widya Mandala Catholic University, Surabaya) for fruitful discussion.

\section{AUTHORS CONTRIBUTIONS}

All the authors have contributed equally

\section{CONFLICT OF INTERESTS}

\section{Declared none}

\section{REFERENCES}

1. Needs CJ, Brooks PM. Clinical pharmacokinetics of the salicylates. Clin Pharmacokinet 1985;10:164-77.
2. Levy G. Clinical pharmacokinetics of aspirin. Pediatrics 1978;62(5 Suppl 2):867-72.

3. Fu CJ, Melethil S, Mason WD. The pharmacokinetics of aspirin in rats and the effect of buffer. J Pharmacokinet Biopharm 1991;19:157-73.

4. Nagelschmitz J, Blunck M, Kraetzschmar J, Ludwig M, Wensing G, Hohlfeld T. Pharmacokinetics and pharmacodynamics of acetylsalicylic acid after intravenous and oral administration to healthy volunteers. Clin Pharmacol 2014;6:51-9.

5. Byod EM. The acute oral toxicity of acetylsalicylic acid. Toxicol Appl Pharmacol 1959;1:229-39.

6. Roderick PJ, Wilkes HC, Meade TW. The gastrointestinal toxicity of aspirin: an overview of randomised controlled trials. Br J Clin Pharmacol 1993;35:219-26.

7. Caroline, Foe K, Esar SY, Retnowati E, Soewandi A, Wihadmadyatami $\mathrm{H}$, et al. Evaluation of analgesic and antiplatelet activity of 2-((3-(Chloromethyl)benzoyl)oxy) benzoic acid. prostaglandins and other lipid mediator. Prostaglandins Other Lipid Mediator 2019;145:106364.

8. Saeed AM, Hamzah MJ, Ahmed NQ. Quantitative assay of aspirin and (Salicylic Acid and Heavy Metals as Impurities) in Iraqi's market aspirin tablets using different analytical methods. Int J Appl Pharm 2018;10:167-72.

9. Pisal P, Nigade G, Kale A, Pawar S. Development and validation of stability indicating RP-HPLC method for simultaneous determination of aspirin, rosuvastatin, clopidogrel in bulk and pharmaceutical dosage form. Int $J$ Pharm Pharm Sci 2018;10:51-6.

10. U. S. Department of Health and Human Services Food and Drug Administration Center for Drug Evaluation and Research (CDER) Center for Veterinary Medicine (CVM), Bioanalytical Method Validation; 2018.

11. Ramesh D, Habibuddin M. Development and validation of RPHPLC method for the determination of alvimopan in rat plasma. Int J Pharm Pharm Sci 2018;10:124-9.

12. Togami K, Fukuda K, Yamaguchi K, Chono S, Tada H. Facile and sensitive HPLC-UV method for determination of nintedanib in rat plasma. Int J Pharm Pharm Sci 2018;10:133-7.

13. Melo A, Almeida HL, Ferreira C, Sousa N, Pego JM. Exposure to ketamine anesthesia affects rat impulsive behavior. Front Behav Neurosci 2016;10:226.

14. Wientjes MG, Levy G. Nonlinear pharmacokinetics of aspirin in rats. J Pharmacol Exp Ther 1988;245:809-15. 